\title{
Skin tissue healing induced by coherent (laser) or non-coherent (LED) light therapy on aged rats
}

\begin{abstract}
Objectives: The purpose of this study was to evaluate the effect of low level laser therapy compared to light emitting diode (LED) therapy on the process of skin healing in aged rats.
\end{abstract}

Background data: Studies demonstrated the effectiveness of therapy with coherent light in the visible spectrum to optimize the process of tissue repair, and some studies suggests that comparable effectiveness could be reached with the lower costs noncoherent light in the same spectral region.

Materials and methods: We used 54 elderly male albino Wistar rats (14 months old) which were submitted to surgical lesions in the dorsum, with a punch of $0.8 \mathrm{~cm}$ diameter. The animals were separated into: three groups were selected as controls, three groups were treated with laser $(660 \mathrm{~nm}, 30 \mathrm{~mW})$ and three groups were treated with LED (640 nm, $40 \mathrm{~nm}$ bandwidth, $54 \mathrm{~mW})$. The lesions of the control group did not receive any light therapy. The lesion's treatments in the laser and LED groups were initiated $30 \mathrm{~min}$. after injury with fluence of $6 \mathrm{~J} / \mathrm{cm}^{2}$ and repeated every $48 \mathrm{~h}$ in three application's sessions. Animals were sacrificed at the 144,312 and $480 \mathrm{~h}$ postsurgery. Histomorphological and histomorphometrical parameters were quantified in the lesioned areas.

Results: showed an increase in the number of inflammatory cells, blood vessels, fibroblasts and collagen in all treated groups, demonstrating that the laser and LED improved the quality of the heal in the elderly animals.

Conclusion: The LED therapy promoted better healing quality than laser

Keywords: laser, LED, wound healing, tissue repair, animals
Volume I Issue 5 - 2017

\author{
João Paulo Alves do Couto, 1,2 Renata \\ Amadei Nicolau, ${ }^{2}$ Egberto Munin, ${ }^{3}$ Miguel \\ Angel Salgado Castillo, ${ }^{4}$ Priscila Silva Fadin, ${ }^{2}$ \\ Landulfo Silveira $\mathrm{Jr}^{3}$ \\ 'Faculdades Integradas do Extremo Sul da Bahia-Unesulbahia, \\ Brazil \\ ${ }^{2}$ Institute of Reaearch and Development-IP\&D, Universidade do \\ Vale do Paraíba-UNIVAP, Brazil \\ ${ }^{3}$ Universidade Anhembi Morumbi, Instituto de Engenharia \\ Biomédica/CITÉ, Brasil \\ ${ }^{4}$ Faculdade de Odontologia de São José dos Campos, \\ Universidade Estadual Paulista Júlio de Mesquita Filho-UNESP, \\ Brazil
}

Correspondence: João Paulo Alves do Couto, Faculdades Integradas do Extremo Sul da Bahia-Unesulbahia, Curso de Fisioterapia, Rod. BR 367, km I4, Eunápolis, BA, Brazil, Zip 45820-000, Tel +55 (73) 328I-4342, Fax +55(73) 328I-4342, Email jcouto@unece.br

Received: May 25, 2017 | Published: September 15, 2017

\section{Introduction}

Healing is a complex biological process, which begins immediately after injury. In the elderly, healing occurs in a slow fashion; collagen quality is different, with lower amounts of fibroblasts and transport of nutrients is dermis/epidermis was difficulty. Since life expectancy of the world population is increasing, a tool for a rapid tissue repair that also improves the quality of the healing in different clinical/surgical situations would help reaching wellness. ${ }^{1}$ In the last decades, several works evaluated the effectiveness of low power laser therapy (coherent light) in the healing process. Light carries energy that deposited in the cell organelles (mainly mitochondria) of injured tissues and increases the level of biochemical reactions at cellular level, increasing cell metabolism and modulating positively the healing tissue..$^{2-6}$

Compared to the coherent, monochromatic laser sources, light emitting diodes (LEDs) are a non-coherent, low-cost option in applications where visible and infrared light with reasonable monochromaticity are needed. Recently the effect of low power LED therapy in the tissue healing process has been evaluated. Some authors observed that, in some cases, LED therapy provided better results than the ones obtained with laser therapy in tendons, skin, bones and ligaments. ${ }^{7-9}$ Considering the lack of studies about the effect of phototherapy (laser or LED) on the process of skin repair in aging organisms, the objective of this work was to evaluate the efficacy of laser and LED therapy (laser:660nm and 30mW; LED:640nm, $40 \mathrm{~nm}$ bandwidth and $54 \mathrm{~mW}$ ) with fluence of $6 \mathrm{~J} / \mathrm{cm}^{2}$, repeated every $48 \mathrm{~h}$ in three applications, on the early wound healing process in the skin of elderly rats compared to controls after 144,312 and $480 \mathrm{~h}$ postsurgery.

\section{Materials and methods}

\section{Animals}

This research protocol followed the ethical principles of the Brazilian Guidelines for Research Involving Animals - COBEA (Protocol $n^{\circ}$ A94/CEP/2007). In this experimental protocol 54 albino male Wistar rats were used with a weight of $500 \mathrm{~g}$ and age of 14 months old. The animals were submitted to an adaptation period of 5 days in the vivarium, under a room temperature of $22^{\circ} \mathrm{C}$ and light/ dark cycles of $12 \mathrm{~h}$. All animals were randomly separated into nine groups of six animals per group (Table 1): three groups were selected as controls (no therapy), three groups were treated with laser and three groups were treated with LED.

\section{Surgical procedure}

All animals received a pretreatment with subcutaneous injection of atropine $(0.04 \mathrm{ml} / 100 \mathrm{~g}$ of body weight), waiting $15 \mathrm{~min}$. before the anaesthetic procedure. Anaesthesia was established by injecting ketamine chloridrate $10 \%$ (Cetamin10\%, Syntec, SP, Brazil), $0.1 \mathrm{ml} / 100 \mathrm{~g}$ body weight and xylazine chloridrate $2 \%$ (Xilazin2\%, Syntec, SP, Brazil), $0.1 \mathrm{ml} / 100 \mathrm{~g}$, intramuscularly with an insulin syringe of $1 \mathrm{ml} .{ }^{10}$ After anaesthesia, the animals were shaved in 
the dorsal (back) region with razor blades and soap. Antisepsis of the region was perfomed, with subsequent incision of a circular punch $(0.8 \mathrm{~cm}$ diameter), with a depth of about $1 \mathrm{~mm}$, to remove the epithelium with no damage of the underlying tissues.

\section{Laser and LED therapy}

Groups LAS144, LAS312 and LAS480 were submitted to the laser therapy at times of 144,312 and $480 \mathrm{~h}$, respectively (Table 1) with an equipment furnishing continuous wave laser emission (model BioWave LLLT Dual, InGaAlP, 660nm, 30mW, Kondortech, SP, Brazil), distributed in an irradiation area of $0.5 \mathrm{~cm}^{2}$ on the top of the incised region. In order to accomplish the energy fluence of $6 \mathrm{~J} / \mathrm{cm}^{2}$, the irradiation time was set to 100 s. Groups LED144, LED312 and LED480 were submitted to the LED therapy at times of 144, 312 and $480 \mathrm{~h}$, respectively (Table 1) with prototype equipment built for the experiment, made up of "one surrounded by six" red LEDs (GaAlAs, 640nm, 40nm FWHM bandwidth, 54mW), distributed in an irradiation area of $0.5 \mathrm{~cm}^{2}$ on the top of the incised region. To accomplish the fluence of $6 \mathrm{~J} / \mathrm{cm}^{2}$, the irradiation time was set to $60 \mathrm{~s}$. The optical power output of both light sources was surveyed prior to the experiments by means of a broadband optical meter (model 13 PEM001/J, Melles Griot, California, USA). Both irradiation sources were placed in contact to the animal's skin during irradiation, protected by a transparent PVC film to prevent contamination.

Table I Experimental groups and time of sacrifice

\begin{tabular}{|c|c|c|c|}
\hline \multirow[b]{2}{*}{ Group } & \multicolumn{3}{|c|}{ Time of sacrifice post-surgery } \\
\hline & $144 \mathrm{~h}$ & $312 \mathrm{~h}$ & $480 \mathrm{~h}$ \\
\hline Control $(n=18)$ & CTRI44(n=6) & CTR3 I $2(n=6)$ & CTR480 $(n=6)$ \\
\hline Laser $(n=18)$ & LASI $44(n=6)$ & $\operatorname{LAS} 312(n=6)$ & $\operatorname{LAS} 480(n=6)$ \\
\hline LED $(n=18)$ & LED I 44(n=6) & LED3 $12(n=6)$ & LED480 $(\mathrm{n}=6)$ \\
\hline
\end{tabular}

\section{CTR, control; LAS, laser; LED, light emitting diode.}

For the therapeutic procedure, the animals were placed on a table in the prone position, immobilised manually without sedation. The tip of the irradiation source was kept in contact with the animal's injured skin during irradiation, forming an angle of $90^{\circ}$ from the wound. The therapeutic procedure was initiated $30 \mathrm{~min}$. after injury with a single light dose and was repeated every $48 \mathrm{~h}$, with a total of three applications. All animals were manipulated by the same person and received the same care.

\section{Sacrifice of animals}

The animals were sacrificed in time intervals as shown in Table 1 for sacrifice the same anaesthesia procedure was used as previously described for surgery, and after being anaesthetised, animals received intracardiac injection of potassium chloride $10 \%(\mathrm{KCl} 10 \mathrm{~mL}$, Isofarma, $\mathrm{CE}$, Brazil). The region where the circular incision was made was removed and fixed by immersing in $10 \%$ formaldehyde solution for $24 \mathrm{~h}$ and subsequently submitted to histological processing.

\section{Histomorphometry}

After fixation, all samples underwent standard histological technique. There were eight sections per animal: four sections were stained with hematoxylin and eosin (H\&E) to observe tissue general structure and four were stained with Masson's trichrome to observe collagen fibres. Digital photomicrographies were obtained with Leica optical microscope at $40 \mathrm{X}$ magnification objective and the images were stored by using Qwin programme, which standardised the intensity of the microscope light and the height of the condenser lens. For statistical purposes we analysed four fields per slide in a total of four slides per animal, two stained with H\&E and two with Masson's trichrome. The digital photomicrographies obtained from the histological cuts were analysed with the ImageJ software for the quantification of inflammatory cells, blood vessel neoformation and fibroblasts (H\&E) and collagen deposition (Masson's trichrome).

\section{Statistical analysis}

The one-way analysis of variance (ANOVA), complemented by the Bonferroni post-test ${ }^{10}$ was applied to all columns, with the nullhypothesis stating that there is no variation among laser, LED and control groups in the time of sacrifice, with a significance level of $5 \%$. The software used for statistics was the InStat2.05 (GraphPad, CA, USA) based on the images of the histopathological cuts measured through Image.

\section{Results}

For the counting of inflammatory cells, blood vessels, fibroblasts and amount of collagen, two regions of the dermis were selected, superficial and deep, and the results were presented in (Tables 2-5). The H\&E photomicrographs (40X) of the superficial and deep layer used in the counting are seen in Figures $1 \& 2$ respectively.

Table 2 Results of the counting of inflammatory cells: I44, 3 I 2 and $480 \mathrm{~h}$ post-injury in control, laser and LED groups

\begin{tabular}{|c|c|c|c|c|c|}
\hline \multicolumn{6}{|c|}{ Number of inflammatory cells Per $55,500 \mathrm{mM}^{2}$ area (mean \pm standard deviation) } \\
\hline & CTR & & LAS & & LED \\
\hline Time (h) & Superficial & Deep & Superficial & Deep & Superficial \\
\hline 144 & $127.0 \pm 22.4$ & II $0.9 \pm 8.0 \mathrm{a}, \mathrm{b}, \mathrm{e}$ & $163.2 \pm 21.2 \mathrm{a}, \mathrm{b}$ & $97.0 \pm 14.8 \mathrm{a}, \mathrm{b}$ & $219.9 \pm 73.9 \mathrm{a}, \mathrm{b}$ \\
\hline 312 & $48.9 \pm 6.2$ & $45.1 \pm 3.3 \mathrm{a}$ & $45.1 \pm 4.4 a$ & $60.0 \pm 5.3 \mathrm{a}, \mathrm{c}$ & $56.8 \pm 12.2 \mathrm{a}$ \\
\hline 480 & $34.5 \pm 3.4$ & $37.3 \pm 2.5 b$ & $19.5 \pm 2.4 \mathrm{~b}$ & $23.7 \pm 6.3 b, c$ & $14.3 \pm 2.3 \mathrm{~b}$ \\
\hline
\end{tabular}

Results were considered statistically significant ( $p<0.05$ ) for: a) I44 vs 3।2, b) I44 vs 480, c) 3 I 2 vs 480 (intra-group); d) CTR vs LAS, e) CTR vs LED, f) LAS vs LED (inter-groups) 
Table 3 Result of the counting of blood vessels: I44, 312 and $480 \mathrm{~h}$ post-injury in control, laser and LED groups

\begin{tabular}{|c|c|c|c|c|c|c|}
\hline \multicolumn{7}{|c|}{ Number of blood vessels per $55,500 \mathrm{mM}^{2}$ area (mean \pm standard deviation) } \\
\hline & CTR & & LAS & & LED & \\
\hline Time (h) & Superficial & Deep & Superficial & Deep & Superficial & Deep \\
\hline 144 & $1.8 \pm 0.6$ & $3.2 \pm 0.7$ & $1.3 \pm 0.7$ & $1.3 \pm 0.4$ & $1.0 \pm 0.4$ & $2.5 \pm 0.4$ \\
\hline 312 & $1.4 \pm 0.4$ & $2.3 \pm 0.5$ & $1.7 \pm 0.4$ & $3.6 \pm 0.3$ & $1.5 \pm 0.5$ & $3.1 \pm 0.6$ \\
\hline 480 & $1.8 \pm 0.5$ & $1.9 \pm 0.3$ & $2.1 \pm 0.5$ & $2.3 \pm 0.6$ & $0.9 \pm 0.3$ & $2.2 \pm 0.7$ \\
\hline
\end{tabular}

Results were considered statistically significant ( $p<0.05$ ) for:a) I 44 vs 3 । 2 , b) I 44 vs 480 , c) 3 I 2 vs 480 (intra-group); d) CTR vs LAS, e) CTR vs LED, f) LAS vs LED (inter-groups)

Table 4 Results of the counting of fibroblasts: I44, 312 and $480 \mathrm{~h}$ post-injury in control, laser and LED groups

\begin{tabular}{|c|c|c|c|c|c|c|}
\hline \multicolumn{7}{|c|}{ Number of fibroblasts per $55,500 \mathrm{mM}^{2}$ area (mean士standard deviation) } \\
\hline & CTR & & LAS & & LED & \\
\hline Time (h) & Superficial & Deep & Superficial & Deep & Superficial & Deep \\
\hline 144 & $104.8 \pm 19.2 \mathrm{~d}$ & $92.1 \pm 5.9 \mathrm{~b}, \mathrm{~d}$ & $39.4 \pm 10.0 \mathrm{a}, \mathrm{d}$ & $44.6 \pm 2.4 d, f$ & $100.2 \pm 28.4$ & $106.7 \pm 11.4 a, b, f$ \\
\hline 312 & $85.5 \pm 9.2$ & $66.3 \pm 4.3 \mathrm{c}$ & $101.1 \pm 11.3 \mathrm{a}$ & $78.3 \pm 8.3$ & $99.1 \pm 5.1$ & $73.8 \pm 5.7 \mathrm{a}$ \\
\hline 480 & $56.4 \pm 6.4$ & $33.4 \pm 3.5 b, c$ & $71.6 \pm 5.7$ & $61.4 \pm 3.8$ & $52.1 \pm 6.5$ & $48.6 \pm 4.5 b$ \\
\hline
\end{tabular}

Results were considered statistically significant ( $p<0.05$ ) for: a) I 44 vs 3 । 2, b) I 44 vs 480 , c) 3 I 2 vs 480 (intra-group); d) CTR vs LAS, e) CTR vs LED, f) LAS vs LED (inter-groups).

Table 5 Results of the amount of collagen: I44, 312 and $480 \mathrm{~h}$ post-injury in control, laser and LED groups

\begin{tabular}{|c|c|c|c|c|c|c|}
\hline \multicolumn{7}{|c|}{ Amount of collagen per $55,500 \mathrm{Mm}^{2}$ area (mean士standard deviation) } \\
\hline \multirow[b]{2}{*}{ Time (h) } & \multicolumn{2}{|l|}{ Ctr } & \multicolumn{2}{|l|}{ Las } & \multicolumn{2}{|l|}{ Led } \\
\hline & Superficial & Deep & Superficial & Deep & Superficial & Deep \\
\hline 144 & $33775 \pm 904 a, b, d, e$ & $36976 \pm 767$ e & $4 \mid 785 \pm 626 d$ & $3987| \pm| 405 f$ & $45747 \pm 1613 \mathrm{e}$ & $47257 \pm \mid 291 \mathrm{e}, \mathrm{f}$ \\
\hline 312 & $40287 \pm 1768 \mathrm{a}, \mathrm{d}, \mathrm{e}$ & $40999 \pm|26|$ & $4627 I \pm 548 d$ & $45022 \pm 943$ & $48611 \pm 1015 \mathrm{e}$ & $46169 \pm 1987$ \\
\hline 480 & $44264 \pm 755 b, e$ & $41998 \pm 1785$ & $47025 \pm 610$ & $45346 \pm 829$ & $497 I I \pm 247 e$ & $45790 \pm 1627$ \\
\hline
\end{tabular}

Results were considered statistically significant ( $p<0.05$ ) for: a) I44 vs 3 । 2, b) I44 vs 480 , c) 3 । 2 vs 480 (intra-group); d) CTR vs LAS, e) CTR vs LED, f) LAS vs LED (inter-groups)

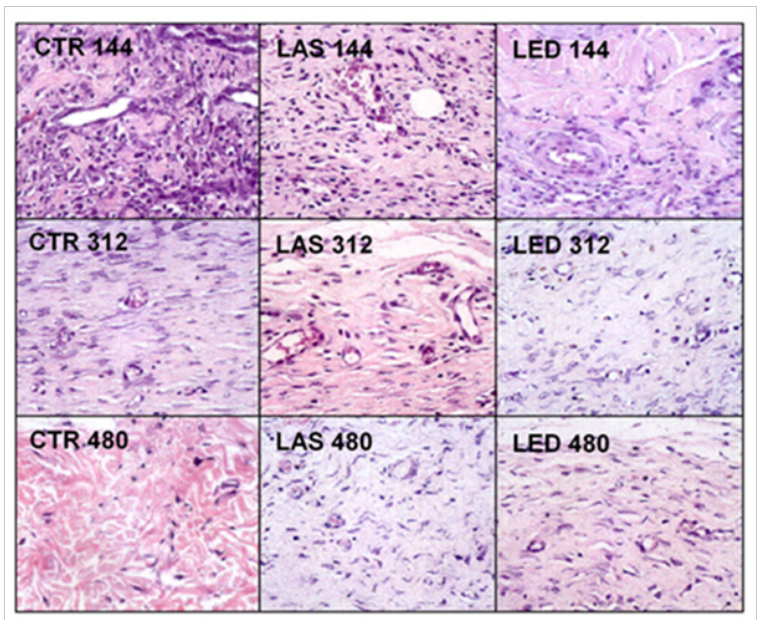

Figure I Photomicrographs of the superficial dermis of $(A)$ control, (B) lasertreated group and (C) LED-treated group, at different times of healing (I44, 312 and 480 h). H\&E, 40X.

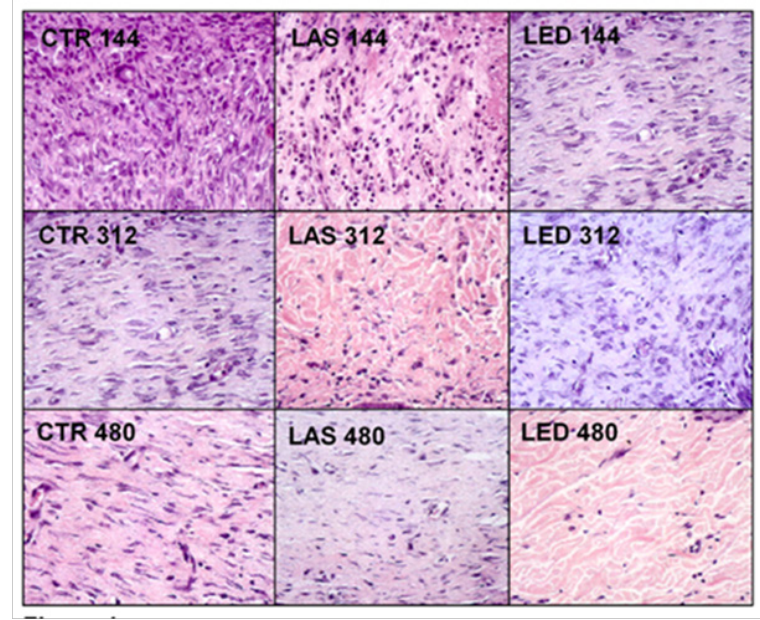

Figure 2 Photomicrographs of the deep dermis of (A) control, (B) lasertreated group and $(C)$ LED-treated group, at different times of healing (I44, 312 and $480 \mathrm{~h}) . \mathrm{H} \& \mathrm{E}, 40 \mathrm{X}$.

Citation: Couto JPA, Nicolau RA, Munin E, et al. Skin tissue healing induced by coherent (laser) or non-coherent (LED) light therapy on aged rats. Int Phys Med Rehab J. 2017;1 (5):I32-137. DOI: I0.15406/ipmrj.2017.01.00029 


\section{Inflammatory cells}

Figure 1 shows the counting of inflammatory cells in the experimental groups. In the region of the superficial dermis, the highest concentration of inflammatory cells was found in the LED144 group compared to the other groups. The LED group, at the superficial dermis, showed the greatest reduction in the number of inflammatory cells at the end of the study. The counting of inflammatory cells is shown in Table 2. In the evaluation of intra-group differences (comparison between different periods of treatment in the same group), the counting of inflammatory cells in the superficial dermis of the LAS144 group was significantly higher compared to the LAS312 and LAS480 groups $(\mathrm{p}<0.05$ and $\mathrm{p}<0.01$, respectively). The same occurred for the LED144 group, which had a significantly higher count compared to the LED312 and LED480 groups ( $<<0.001$ for both groups). It was not found statistically significant differences in the inter-group differences (comparing different groups).

Regarding the intra-group evaluation in the deep dermis, the count of inflammatory cells in the CTR144 group was significantly higher than CTR312 and CTR 480 groups ( $<<0.001)$, the same occurring for the LAS144 group versus LAS312 ( $<<0.05)$, LAS144 versus LAS480 and LAS312 versus LAS480 ( $<<0.001$ and $p<0.05$, respectively). The LED144 group was significantly higher than the LED480 group $(p<0.001)$. Regarding the inter-group analysis in the deep dermis, the number of inflammatory cells in the LED144 group was significantly higher than the CTR144 group ( $<<0.01)$.

\section{Number of vessels}

In the evaluation of intra-group and inter-group differences in the number of vessels (Table 3), no significant differences were found comparing the experimental groups. Despite this not-statistically significant result, the lowest values were found in the LED group at the superficial dermis independent of the time of sacrifice, especially at LED480. In both LAS and LED groups the higher number of blood vessels occurred at $312 \mathrm{~h}$ after injury in the deep dermis. The highest number of vessels was found in the LAS312 group in the deep dermis compared to all other groups.

\section{Fibroblasts}

Table 4 shows the counting of the number of fibroblasts in the CTR, LAS and LED groups. In the intra-group analysis of the superficial dermis, a statistically significant difference in the counting of fibroblasts $(p<0.05)$ was shown between the LAS144 and LAS312, with it being higher in the latter. In the inter-group analysis in the superficial dermis, the number of fibroblasts in the CTR144 group was higher than in the LAS144 group $(\mathrm{p}<0.05)$ In the deep dermis, the intra-group analysis showed that there were no statistically significant differences for the time intervals in the LAS group. The CTR144 and CTR312 groups showed a significantly higher number of fibroblasts when compared to the CTR480 group ( $p<0.01$ and $p<0.05$, respectively). The LED144 group showed significantly higher when compared to LED312 $(\mathrm{p}<0.05)$ and LED480 $(\mathrm{p}<0.001)$. In the intergroup evaluation at the deep dermis, there was a statistically significant difference between the CTR144 group versus LAS144 and LAS144 versus LED144 ( $<<0.001$ and $p<0.001$, respectively), with the LAS group showing lower values in both groups in this early stage. The CTR480 group showed a significantly lower number of fibroblasts, both intra- and inter-groups. The largest number of fibroblasts was found in the LED144 group in the deep dermis (Figure 2).

\section{Collagen}

The amount of collagen for all groups in the selected time intervals are presented in Table 5. The result of the intra-group evaluation in the superficial dermis showed that the percentage of collagen in CTR312 and CTR480 groups are significantly higher $(p<0.05$ and $p<0.001$, respectively) than the CTR144. In the inter-group evaluation of the superficial dermis, a statistically significant difference was found between the CTR144 and LAS144 groups $(p<0.01)$ and CTR144 and LED144 $(\mathrm{p}<0.001)$. It was observed that the CTR312 group was significantly lower than the LAS312 $(\mathrm{p}<0.01)$ and LED312 group $(\mathrm{p}<0.001)$. The CTR480 group was found to have less collagen than the LED480 group $(\mathrm{p}<0.05)$. The LAS and LED groups were found to have a higher level of collagen than the CTR group at all times, especially the LED480, which showed the highest amount of collagen in superficial dermis.

In the intra-group analysis of the deep dermis, it was demonstrated no statistically significant difference in any of the groups. The intergroup analysis showed an increased percentage of collagen in the LED144 compared to the CTR144 group $(p<0.001)$ and the LAS144 group $(\mathrm{p}<0.05)$. The LED groups obtained higher percentages in all groups.

\section{Discussion}

The ability to heal wounds deteriorates with age, reducing or inhibiting the re-epithelialisation. Analysis of the age-related changes in healing capacity demonstrates that every phase of healing undergoes characteristic age-related changes, including enhanced platelet aggregation, increased secretion of inflammatory mediators, delayed infiltration of macrophages and lymphocytes, impaired macrophage function, decreased secretion of growth factors, delayed re-epithelialisation, delayed angiogenesis and collagen deposition, reduced collagen turnover and remodelling, and decreased wound strength. ${ }^{11}$

The first stage of healing is the inflammatory phase and is characterised by increased blood flow, microvascular alterations, migration, and accumulation of inflammatory cells in the lesion site. ${ }^{12}$ The results of this study showed that the treated groups presented a higher concentration of inflammatory cells in the lesion site at the surface level in the initial stage of repair, mainly in the LED group compared to control. However, in the final phase of the study (480 $\mathrm{h}$ after injury), these proportions are inversed (phase of eminent synthesis). This is consistent with previous studies that employed laser radiation in the red portion of the spectrum for stimulation of the tissue repair process in skin wounds in the inflammatory phase. ${ }^{5} \mathrm{~A}$ few studies have been performed using LED therapy in young animals, which reported an increase in the amount of inflammatory cells, but no study was conducted in older animals. ${ }^{13}$ The pro-inflammatory cellularity observed in the treated groups suggests the occurrence of a chemotaxis effect as described in low level laser therapy ${ }^{14-16}$ but not noted previously with LED therapy.

The intense presence of inflammatory cells, as observed in the LED groups, can provide most responsive areas to a septic process, as pointed out by previous studies with electromagnetic radiation in the red. ${ }^{15}$ At the deep tissue level, the treated groups presented lesions with less cellularity, implying normalisation of the tissue reactivity, such as improving $\mathrm{pH}$ decreasing prostaglandin production, increasing mitochondrial activity and oxygen radicals, which stimulate the 
respiration chain and ATP production. This leads to mitosis and cell proliferation with synthesis of DNA and RNA. ${ }^{17-19}$ These data indicate an optimisation in the starting of tissue repair (inflammatory phase) in elderly organisms. In the proliferative phase of the repair process, epithelium formation to cover the wound surface occurs. In this process there are mechanisms of fibroblasts proliferation, collagen and other extracellular matrix deposition and new blood vessel development. ${ }^{20-24}$ The evaluation of blood vessel concentration is extremely difficult in conventional histological techniques, considering the topographical features of the vessels (overlap of vessels). Errors may occur in their scores, leading to false results in the number of vessels measured in the tissue.

The number of blood vessels, together with the other parameters, cam be used to estimate the formation of granulation tissue in phototherapy-treated tissues. There were no statistically significant differences between the treated and control groups regarding those parameters, which may suggest the absence of a neovascularisation stimulus with the parameters used in laser and LED therapy. These data are in agreement with the results of Rabelo et al. ${ }^{24}$ which found that diabetic and non-diabetic animals treated with laser showed a reduction in the number of vessels during the first week of tissue repair, and the number of vessels was even lower in animals treated with laser. In assessing the number of vessels in subsequent phases, the present study showed angiogenesis in all groups, with a significant increase in the deep dermis of treated groups. Similarly, was observed that the presence of angiogenesis in the deeper regions of control animals was slightly higher compared to the groups treated with light laser. ${ }^{18}$ The formation of new vessels is due to the existence of vessels adjacent to the lesion. The endothelial cells begin the process of angiogenesis as a response to the damage..$^{23}$

The number of fibroblasts between all studied groups was not significantly different in the proliferative phase $(312 \mathrm{~h})$, corroborating the studies by Rabelo et al. ${ }^{24}$ for wounds of healthy animals treated with red laser $(632.8 \mathrm{~nm})$. However, significant differences were observed in the number of fibroblasts for the LED group compared to the laser group at $144 \mathrm{~h}$, which agrees with studies carried out by Vinck et al. ${ }^{25-26}$ These authors found that LED radiation in the 660 and $570 \mathrm{~nm}$ region promotes an increase in the number of fibroblasts when compared to LED at $950 \mathrm{~nm}$ and laser at $830 \mathrm{~nm}$ after $144 \mathrm{~h}$. Even outside the proliferative phase, these data are fundamental to understanding the results regarding collagen obtained in the synthesis phase for the groups treated with light, since fibroblasts are responsible for collagen deposition and the sites which had more collagen were the ones with higher fibroblasts.

The fibroblast plays a crucial role in wound healing; most studies published in the literature on low-level laser therapy examined their effects on fibroblasts, cell growth, migration and collagen production ${ }^{6}$. Previous studies demonstrated an increased cellular metabolism, with a higher number of mitochondria in the cytoplasm of fibroblasts in irradiated animals compared to control ones. The increased number of mitochondria was indicative of increased energy demand, which may have caused the increase in the number of fibroblasts and/or increased collagen synthesis. ${ }^{2,13}$ These data are in accordance with the results presented here, in which CTR and LED groups showed the highest numbers of fibroblasts in $144 \mathrm{~h}$, while the LAS group showed the highest number of fibroblasts in $312 \mathrm{~h}$ and $480 \mathrm{~h}$ when compared to the other two groups. Both treated groups showed a statistically significant higher amount of collagen compared to the control, indicating an increased fibroblast metabolism as suggested by another researches. ${ }^{2,13,14}$

Considering the anti-inflammatory effects of laser in the red it is reasonable to assume that such radiation could influence the production of inflammatory mediators such as cytokines. TGF- $\beta$ is an important cytokine that acts during the healing process by activating cell proliferation. The laser may act on the macrophages in the respiratory chain, increasing production of TGF- $\beta$, which inhibits macrophages diapedesis in the conjunctive tissue. ${ }^{1}$ This mechanism may explain the low number of macrophages and oedema in the irradiated dermis compared to the control dermis. The TGF- $\beta$ is related to a number of biological effects, such as induction of fibroblast differentiation into myofibroblasts stimulation of collagen synthesis, and angiogenesis. ${ }^{27}$ Histological observations showing that, after diminishing the excess of inflammatory cells, there is an increase in the formation of collagen fibres and the recovery of tissue continuity. ${ }^{10}$ Oppositely, there is evidence that inflammation leads to poor formation of collagen fibres and discontinuity of healed tissue ${ }^{20}$ corroborating the findings of this study, where the light-treated group presented an increased number of inflammatory cells in the dermis surface in the initial phase $(144 \mathrm{~h})$ when compared to other groups, and presenting a significant difference in the amount of collagen, where the major deposits were observed in the LED-treated groups followed by the laser-treated groups. The remodelling phase is the last stage of healing, where a reorganisation of collagen takes place, leading to a greater tensile strength. ${ }^{24}$ Sanatim et al. ${ }^{28}$ showed that a better healing of injured tissue was found in the treated groups, with emphasis on the elderly group. Our work confirms the findings of Sanatim et al..$^{28}$ with an increased amount of collagen in the lesioned area of light-treated groups compared to untreated groups, with the LED-treated group more evident.

Despite the differences in the power of both light sources used in the study, the energy was kept the same. Almeida-Lopes et al. ${ }^{29}$ using lasers at $670,692,780$ and $786 \mathrm{~nm}$ with the same fluence (2 $\mathrm{J} / \mathrm{cm}^{2}$ ) for gingival fibroblast irradiation, showed that the infrared laser induced a higher cell proliferation than visible laser when the power outputs were higher (five-fold); however, lasers of equal power output presented similar effect on cell growth independently of their wavelengths. In this study, the LED promoted better response, which could be in some extent related to the higher power.

\section{Conclusion}

It has been evidenced that the treatment of lesioned skin with coherent and incoherent light sources (laser and LED, respectively) favored the process of wound healing in elderly rats, and the animals treated with LED at $640 \mathrm{~nm}, 54 \mathrm{~mW}$ and $6 \mathrm{~J} / \mathrm{cm}^{2}$ showed better results in terms of collagen deposition, fibroblasts proliferation and inflammatory cellular response when compared to the laser at $660 \mathrm{~nm}$, $30 \mathrm{~mW}$ and same fluence.

\section{Acknowledgements}

L Silveira Jr \& RA Nicolau thanks National Counsel of Technological and Scientific Development (CNPq) for the Productivity Fellowship (305610/2008-2 and 314455/2009-4).

\section{Conflict of interest}

This work is original and is not being considered for publication in no other Journal. We have no conflict of interest because the work was financed by the authors. 


\section{References}

1. Meirelles RHS. Tabagismo e DPOC:dependência e doença-fato consumado. Pulmão RJ - Atualizações Temáticas. 2009;1(1):13-19.

2. Mirra AP, Meireles RHS, Godoy I, et al. associação medica brasileira e agência nacional de saúde suplementar. Diretrizes Clínicas na Saúde Suplementar. Tabagismo, Brazil; 2009.

3. Nazaroff W, Kleipes N. Environmental tobacco smoke particles. In: Morawska L \& Salthammer T, editors. Indoor environment: Airborne particles and settled dust. Hoboken: Wiley; 2004. p . 245-274.

4. World Health Organization. Air quality guidelines for Europe. Copenhage: Denmark; 2007.

5. Schnabel E, Chen C, Koch B, et al. Regional diferences in prediction models of lung function in Germany. Respir Res. 2010;11(40):1-11.

6. Ohar JA, Sadeghnejad A, Meyers DA, et al. Do symptoms predict COPD in smokers? Chest. 2010;137(6):1345-1353.

7. Ulrik CS, Lokke A, Dahl R, et al. Early detection of COPD in general practice. International Int J Chron Obstruct Pulmon Dis. 2011;6:123127.

8. Paes CD, Pessoa BV, Jamami M, et al. Comparação de valores de PFE em uma amostra da população da cidade de São Carlos, São Paulo. $J$ Bras Pneum. 2009;35(2):151-156.

9. Britto RR, Brant TCS, Parreira VF. Avaliação do pico de fluxo expiratório. Recursos Manuais e Instrumentais em Fisioterapia Respiratória. São Paulo: Manole; 2009. p. 33-45.

10. Xu X, Li B. Exposure-response relationship between passive smoking and adult pulmonary function. Am J Respir Crit Care Med. 1995;151(1):4146.

11. Carrey IM, Cook DG, Strachan DP. The effect of environmental tobacco smoke exposure on lung function in a longitudinal study of British adults. Epidemiology. 1999;10(3):319-326.

12. Tanaka GN, Ruas G, Pessoa BV, et al. Comparison of Five portable peak flow meters. Clinics. 2010;65(5):496-474.

13. Quanjer PH, Lebowitz MD, Gregg I, et al. (1997) Peak expiratory flow: conclusions and recommendations of a Working Party of the European Respiratory Society. Eur Respir J. 1997;Suppl 24:S2-8.

14. Giovino GA, Mirza SA, Samet JM, et al. The GATS Collaborative Group. Tobacco use in 3 billion individuals from 16 countries: ananalysis of nationally representative cross-sectional household surveys. Lancet. 2012;380(9842):668-679.
15. World Health Organization. Global status report on non communicable diseases 2010. Geneva: Switzerland; 2011.

16. Cao S, Yang C, Gan Y, et al. The Health effectsof passive smoking: An overview of systematic reviews based on observational epidemiological evidence. PLoS One. 2015;10(10):1371.

17. Tamashiro E, Cohen NA, Palmer JN, et al. Efeitos do cigarro sobre o epitélio respiratório e sua participação na rinossinusite crônica. Braz J Otorhinolaryngo. 2009;175(6):903-907.

18. Oliveira MVC, Sales MPU. Tabagismo passivo. In: Viegas CAA, editor. Diretrizes para cessação do tabagismo. J Bras Pneumol. 2004.

19. McCoy EK, Thomas JL, Sowell RS, et al. Na evaluation of peak expiratory flow monitoring: A comparison of sitting versus standing measurements. J Am Board Fam Med. 2010;23(2):166-170.

20. Silva JA, Fonseca MR, Melo MAV, et al. O peak flow expiratório em mulheres fumantes e não fumantes e suas medidas de confiabilidade. Assobrafir Ciência. 2015;6(1):41-48.

21. Ruivo S, Viana P, Martins C, Baeta C. Efeito do envelhecimento cronológico na função pulmonar. Comparação da função respiratória entre adultos e idosos saudáveis. Rev Port Pneumol. 2009;15(4):629653.

22. Beardsmore CS, Wimpress SP, Thomson AH, et al. Maximum voluntary cough: an indication of air way function. fisiopatol Respir. 1987;23(5):465-472.

23. Jaakkola MS, Jaakkola JJ. Assessment of exposure to environmental tobacco smoke. Eur Respir J. 1997;10(10):2384-2397.

24. US Department of health and human services. The health consequences of involuntary smoking. A report of the surgeon General. public health service, centers for disease control, Center for health promotion and education: USA; 1986.

25. Seelig MF, Campos CRJ, Carvalho JC. A ventilação e a fumaça ambiental de cigarros: um estudo sobre a qualidade do ar de ambientes fechados sujeitos à FAC. Rev da Amrigs. 2005;49(4):253-256.

26. Freitas FS, Parreira VF, Ibiapina CC. Aplicação clínica do pico de fluxo da tosse: uma revisão de literatura. Fisioter Mov. 2010;23(3):495-502.

27. Smith JA, Aliverti A, Quaranta M, et al. Chest wall dynamics during voluntary and induced cough in healthy volunteers. $J$ Physiol. 2012;590(3):563-574.

28. Ishida $\mathrm{H}$, Kobara $\mathrm{K}$, Osaka $\mathrm{H}$, et al. Correlation between peak expiratory flow and abdominal muscle thickness. J Phys Ther Sci. 2014;6(11):1791793. 